Article History:

Submitted:

16 September 2021

Reviewed:

28 December 2021

Edited:

3 January 2022

15 January 2022

Accepted:

15 January 2022

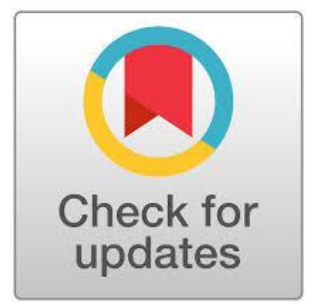

\section{English Education Master Students' Perceptions on \\ Peer Feedback in Academic Writing}

Kristian Florensio Wijaya

Cita Hati Internasional School, Indonesia

kristianw611@gmail.com

DOI: https://doi.org/10.1819g/ftl.v7i1.12751

\begin{abstract}
This present qualitative study aimed to explore English Education Master Students' perceptions on peer feedback in academic writing. One major reason for conducting this study was to enlight ELT parties on maximizing peer feedback activities in academic writing classes. Mixed method was utilized to attain clearer portrayals out of the specific phenomenon based on the statistics and apparent explanations shared by the research participants. 10 online Likert-scale questionnaire items along with 5 open-ended written narrative inquiry questions were administered to 15 English Education Master Students, Sanata Dharma University, batch 2019. The research results strongly suggested EFL educators continually cultivate peer feedback practices in academic writing activities to better promote more enjoyable, meaningful, and holistic learning environments in which learners' target language and future life competencies thrive more fruitfully. To a lesser extent, these specific research results can potentially give more enlightenment for globalized ELT parties concerning to the appropriate utilization of academic writing peer feedback activities in accord with graduate university EFL learners' perspectives.
\end{abstract}

Keywords: Peer feedback; academic writing; English Education Master students; EFL 


\section{Introduction}

Around the globe, graduate learners are commissioned to fully possess a higher degree of academic literacy skills comprising of reading and writing. These two skills mentioned earlier are closely interconnected since reading can extensively provide greater writing assistance for graduate students to synthesize, summarize, paraphrase, and depict all the relevant ideas to be put in the writing. Hirvela and Du (2013) mention that graduate students will be more capable of constructing their ideas clearly and efficiently in their writing products by reading a large quantity of reading texts. However, the nourishment of higher-order thinking skills in academic writing learning enterprises is gradually shifted into a more process-oriented approach where all graduate students must recheck, evaluate, and reverse the writing outcomes. Anchored on this conception, Andrade and Evans (2012) theorize that the major benefit of doing in-depth writing evaluation is to allow writers to create more qualified writing products at the end of the writing session. Moreover, one of the profound writing evaluation stages that graduate students should utilize is revision. Through conscientious writing revision cycle, graduate students will be more capable of depicting clearer ideas, arguments, and contentions to worldwide readers. It can also be stated that they will be more able to produce more effective writing products in which readers have successfully obtained the major essential points from their pieces of writing. This benefit is resonated well with the writing revision theory proposed by Kita et al., (2010) stating that by repeatedly revising their original writings, writers will have broader chances to generate more effective written messages inspiring for the readers to be read.

Concerning the aforementioned argumentations, feedback is also discerned as one of the pivotal focal points that should be capitalized on by EFL teachers and graduate university EFL students in their academic writing learning enterprises to increasingly elevate their writing engagement, autonomous writing characters, and positive writing perceptions. This sense of perspective is well-supported by the theory of academic writing feedback postulated by Carless and Boud (2018) strongly supporting globalized EFL teachers to address more interactive and pleasurable academic writing learning circumstances by harnessing constructive feedback potentially promoting a higher level of writing learning engagement and independent writing behaviors for learners. One of the effective academic writing feedbacks is peer feedback. Bacon 
and Bounty (2020) believed that with the support of peer feedback, EFL learners will be more capable of developing their target language and social skills into the utmost levels. These main benefits are mutually associated with academic writing peer feedback theory adduced by Ajjawi and Boud (2017). It declares that by constantly making use of peer feedback, graduate university EFL learners can progressively hone their higher-order thinking skills in providing relevant suggestions for their learning companions simultaneously resulted in the striking elevation of academic writing learning autonomy. After having been succeeded in embedding this academic writing practice sustainably, graduate university EFL learners have also gained a higher degree of awareness concerning others' writing compositions, styles, and uniqueness leading them to be more competent academicians highly appreciative of all the unique ideas put forth by other learning members. Inspired by these above-explained argumentations, Winstone and Boud (2020) discover that the majority of graduate university EFL learners who were trained to impart more constructive peer feedback through academic writing learning ventures could address a higher level of reverence to other learning counterparts' academic writing products.

Furthermore, graduate university EFL learners earnestly forging their peer feedback skills in academic writing activities can also attain more fruitful academic writing learning merits in terms of the significant improvement of their academic writing skills, the rejuvenation of the prior as well as actual knowledge, and the tangible experiences of exhaustive academic writing learning venture. These 3 other major benefits are tightly interwoven with the finding of Latifi et al., (2021). It was found out that most university EFL learners having been armed with peer feedback practices were more liable to dramatically increase their academic writing competencies, become more open-minded academicians, and experience more pleasurable academic writing learning dynamics. The others indispensable values obtained by graduate university EFL learners after becoming more accustomed to utilizing this academic writing practice is their reasoning and argument competencies are also increased more prolifically since they ought to construct clearer suggestions comprehensible for their learning companions. Bijami et al., (2013) highly prompt EFL teachers all around the globe to infuse consistent peer feedback practices in academic writing learning processes to 
better reinforce their learners' higher-order thinking skills in terms of logical reasoning and argumentation skills.

On the other hand, the peer feedback practices in academic writing are not without drawbacks since graduate university EFL learners still dwelling in developing academic writing competencies can merely impart superficial writing feedback to other capable learning counterparts consisting of vocabulary, grammar, dictions, and punctuations. By experiencing the phenomenon as mentioned earlier, it will be easier for all learners to fall back into demotivating academic writing learning atmosphere in which they will not be motivated anymore to proceed into their ongoing academic writing processes. This unpleasant academic writing learning experience is in conjunction with the theory of academic writing peer feedback shortage devised by Allen and Mills (2016). They state that it is of paramount importance for worldwide EFL teachers to become decent roles models for their learners in addressing more constructive academic writing peer feedback in order to continually corroborate their learners' academic writing learning motivation. In another peer feedback implementation investigation, Wu (2019) unveiled that university EFL learners encountered serious impediments in generating constructive academic writing peer feedback toward other learning members. It is because they only mastered the superficial knowledge of language structure, cohesion and linguistics features.

Five relevant studies have been conducted according to the proposed research theme above. Fithriani (2019) unfolded that the utilization of peer feedback could progressively increase university EFL learners' academic writing skills, qualities, and higher-order thinking skills. In another identical investigation, Fithriani (2019) strongly advised Indonesian university EFL teachers to familiarize their learners with constructive peer feedback in harmony with their academic writing proficiency to promote more meaningful academic writing learning dynamics. Junianti et al., (2020) unveiled that more varied in-depth writing learning strategies should be merged within diverse wide-ranging writing classroom vicinities in terms of planning, logical reasoning, revision, and peer feedback cycles in order to breed more competent academic writers. Mahdiya (2021) highly suggested that Indonesian EFL teachers continuously incorporate constructive peer feedback practices in academic writing learning activities to foster their learners' academic writing motivation, proactiveness, and positive views to the utmost 
levels. In the last study, Rezeki (2017) discovered that in the support of constructive academic writing feedback, university EFL learners were not solely foster their academic writing but also interpersonal skills since they were trained to be more intensively appreciative towards others' academic writing products. None of the previous studies have been conducted to further investigate graduate university EFL learners' perceptions of peer feedback in academic writing to the best of the researcher's knowledge. By conducting this present small-scale qualitative study, it is expected that the obtained results will shed more enlightenment concerning the appropriate implementations of constructive. Peer feedback should be internalized by all Indonesian ELT parties in the future academic writing venture. One research problem was formulated as follows: (1) To what extent did English Education Master Students value the utilization of peer feedback in academic writing?

\section{Literature Review}

\section{Peer Feedback}

As mentioned earlier, the further incorporation of peer feedback can ascertain the more prolific development of EFL learners' academic writing skills, interpersonal skills, positive writing attitudes, and mutual collaborative sharing with others. Price et al., (2011) asserted that the ineluctability of peer feedback in academic writing learning ventures is tangible since EFL learners can potentially establish more robust collaborative networkings and intimate mutual sharings rewarding for the holistic development of their academic writing learning processes. Berggren (2019) articulated that although it takes plenty of time for these benefits to emerge, the sustainable internalization of peer feedback in academic writing learning enterprises can also considerably elevate EFL learners' higher-order thinking skills and learning responsibility since they are strongly required to take charge of other learning companions' progress by imparting more constructive, contextual, and meaningful feedback. This argument is apparently attested by the finding of Mutch et al. (2018), revealing that most university EFL learners having been armed with peer feedback was more capable of maintaining their academic writing learning responsibility, logical reasoning, and critical argumentation skills more efficiently. 
In reverse, there are also many challenges in capitalizing on peer feedback in academic writing learning ventures. First, university EFL learners are highly demanded to construct more robust knowledge toward the academic writing themes put forward by other learning companions. Nicol et al., (2014) accentuated the critical importance of correlating their prior and existing knowledge of the subject-specific matters postulated by other learning community members for all university EFL learners to generate more qualified academic writing products. Second, the placement of more meaning-making academic writing peer feedback is also strongly determined by the maturity, the extant academic writing level, and self-confidence instilled by learners. It can also be phrased that when learners do not fully possess all those 3 attributes, the utilization of academic writing peer feedback will bring about detrimental effects for all learners' community members which are demotivating and frustrating academic writing learning experiences. This contention is mutually linked with the theory of academic writing peer feedback put forward by Evans (2015) pinpointing that the major backwash of internalizing premature academic writing peer feedback is all learners will not be able to navigate their academic writing learning dynamics in a better direction due to the ambiguous, unclear, and irrelevant suggestions suggested by their learning counterparts. Other diminishing factors preventing EFL teachers from implanting constructive peer feedback for their learners in academic writing learning enterprises are the reliability of teachers' feedback and painstaking learning situations endured by all learning community members. It is not secretive that most of our learners are still relying intensively on teachers' feedback in supervising their academic writing processes since they hold a strong contention that suggestions proposed by their teachers are more credible than the feedback put forward by learning companions. Yu and $\mathrm{Hu}$ (2017) unearthed that most Chinese university EFL learners were still abiding by their teachers' feedback in academic writing since they did not put a higher degree of certainty toward the proposed suggestions addressed by their learning partners. While the painstaking processes of maximizing the utilization of peer feedback in academic writing learning dynamics refer to the integration of higher-order thinking skills and highly supportive learning behaviors fully disseminated within all learners by analyzing, synthesizing, and evaluating the whole academic writing ideas profoundly. Zhu and Carless (2018) articulate that it is becoming progressively essential for all learning community members to unite their similar energy, enthusiasm, and 
commitment in capitalizing on peer feedback approach through academic writing learning processes amid academic writing learning complexities unless the upcoming learning breakdowns will be their unintended consequences.

\section{The Integration of Peer Feedback in Academic Writing}

A vast range of globalized EFL teachers and learners still undervalue the utilization of peer feedback in academic writing. Carless and Boud (2018) uncovered that it was explicitly true for worldwide EFL teachers and learners to feel reluctant to utilize peer feedback activities in academic writing enterprises. Thus, Zhu and Carless (2018) strongly remarked that without constructing more obvious objectivities in mind while incorporating peer feedback in academic writing activities, it will be improbable to expect all learners to become more judicious decisionmakers, effective problem-solvers, and strategic thinkers in the future events. Considering all the described phenomena, it is worth suggesting for EFL teachers to introduce their learners to peer feedback activities in order to help them begin seeing that the long-lengthy writing evaluations put forth by their peers can also lead them to academic writing learning success. Zhou et al., (2021) acknowledged that it is exceptionally pivotal for EFL teachers to introduce some meaningful academic writing peer feedback strategies for their learners to not merely transfigure them into more competent academic writers but also broad-minded academicians highly respectful for variegated academic writing products. Cao et al. (2019) mentioned that there are two effective strategies EFL teachers can harness to maximize the continuous utilization of academic writing peer feedback. Firstly, teachers can commission their learners to critically identify their specific academic writing genres, contexts, and topics suitable for worldwide readers. By capitalizing on this first approach in a moment-by-moment manner, it can be ascertained that EFL learners will jointly produce more qualified, appropriate, and understandable academic writing products for their readers. Concerning this first strategy, $\mathrm{Yu}$ and Lee (2016) confirmed that through genre-based academic writing approach, university EFL learners will benefit more from the overall writing qualities improvements, writing peer feedback, and the appropriateness of targeted readers since they have successfully identified the overarching writing genres, contexts, and structure precisely matched with their writing objectivities. Secondly, EFL teachers can play their new roles as supportive academic writing 
learning facilitators vehemently imparting constructive peer feedback, valuable writing guidance, and adequate writing supervision for their learners encountering difficult academic writing learning hurdles. By familiarizing learners with this strategy, they will have wider chances to foster their academic writing competencies and peer feedback strategies since they have clearly obtained the bigger picture of how these effective strategies should run according to the aforementioned teachers' actions. This conception agreed with the study of Chen and $\mathrm{Su}$ (2012) uncovering that through the continual supportive academic writing supervisions as well as the integration between constructive teachers' and peer feedback, learners will potentially attain more satisfying academic writing learning outcomes and harness their peer feedback approaches more meaningfully toward learning partners.

\section{Method}

This present small-scale qualitative study was conducted by using the mixed method to obtain more accurate data. Levitt et al., (2018) state that the primary benefit of the mixed method is to allow the researchers to collect more precise data. To fulfill this research objectivity, the researcher planned to design ten online Likert-scale questionnaire items to investigate more exhaustively English Education Master Students' perceptions on peer feedback in academic writing processes. The researcher's former lecturer validated this set of 10 online Likert-scale questionnaire in order to be eligible for the data gathering processes. The validation process enabled the researcher to administer relevant items to the targeted research participants. The type of validation the researcher underwent was human's validation since the lecturer checked all the items. However, the major drawback of this questionnaire was that no formal types of validation were applied, potentially inducing the generalizability of the obtained data. These items were heavily concerned with English Education Master Students' perceptions on peer feedback in academic writing enterprises. 4 point likert-scale was utilized ranging from strongly disagree, disagree, agree, and strongly agree to reduce the research bias. After obtaining the data derived from this first research instrument, the research also used 5 open-ended written narrative inquiry questions to attain more obvious descriptions regarding the life events disseminated by the targeted interviewees. This set of narrative inquiry questions predominantly covered about the good values, drawbacks, and challenges experienced by 
English Education Master Students while utilizing peer feedback during the academic writing enterprises. These items enabled the researcher to discern the beneficial values, challenges, and implementations of peer feedback in academic writing enterprises, which in turn, could generate richer data. Clandinin and Caine (2013) claim that in light of open-ended written narrative inquiry questions, the research participants will potentially impart more trustworthy data since they will feel secure to disseminate the truth manifested into the stories. The participants in this current qualitative study were 15 English Education Master Students batch 2019, Sanata Dharma University, Yogyakarta. The main reason why the researcher selected them as the research participants were that they had been commissioned to produce at least two qualified academic writing products to be published at either international or national journal articles as one of the prerequisites to graduate. Further, during this long-lengthy academic writing learning process, the lecturers also encouraged them to conduct peer feedback with their trusted learning partners both inside and outside of classroom contexts in order to hone their higher-order thinking skills, academic writing skills, and autonomous learning behaviors. The data gathering processes would be conducted online due to the distant locations experienced by the researcher and research participants. The 10 Likert-scale questionnaire items were administered through Google form to be filled by the targeted research participants voluntarily. While 5 open-ended narrative inquiry questions were distributed to 2 interviewees derived from similar population samplings. During the online data gathering processes, only one research participant did not fill out the Likert-scale questionnaire without clarifying any particular reasons. Follow-up interview questions would be asked to the 3 interviewees to ascertain the robustness of the obtained data. Due to all interviewees restricted ethical considerations assented, the researcher would conceal their real identities to be superseded with some initial names such as interviewees 1 and 2 . For the data analysis processes, the researcher had already expounded all the obtained data in tables and narrative argumentations to impart clearer messages for a worldwide audience. The tables represented 10 online Likert-scale questionnaire items and they were accompanied by some relevant prior findings, theories, and interviewees' excerpts. The researcher analyzed the data by counting the mean score to thoroughly discover the total number of participants who either agree or disagree with the statements forming in this online questionnaire. To reach this 
research objectivity, the researcher planned to utilize open coding in analyzing each finding of the data. By using this research method, all the wider research findings could be pursued in some specific research themes resulting in more obvious explanations enabling all readers to feel easier in following all the ideas, arguments, and contentions presented in this study. Cho and Lee (2014) averred that with the support of open-coding, the researchers were more capable of yielding more constructive, robust, and trustworthy data for worldwide readers due to the rejuvenation of perspectives toward the existent situations.

\section{Findings and Discussions}

This part aimed to critically expound all the obtained findings from the research participants regarding their specific perceptions on peer feedback in academic writing learning enterprises. Those findings can be subdivided into 2 major themes, namely (1) The influential positive impacts promoted by peer feedback and (2) Factors affecting the utmost utilization of peer feedback.

\section{The Obtained Data Taken from the Questionnaire:}

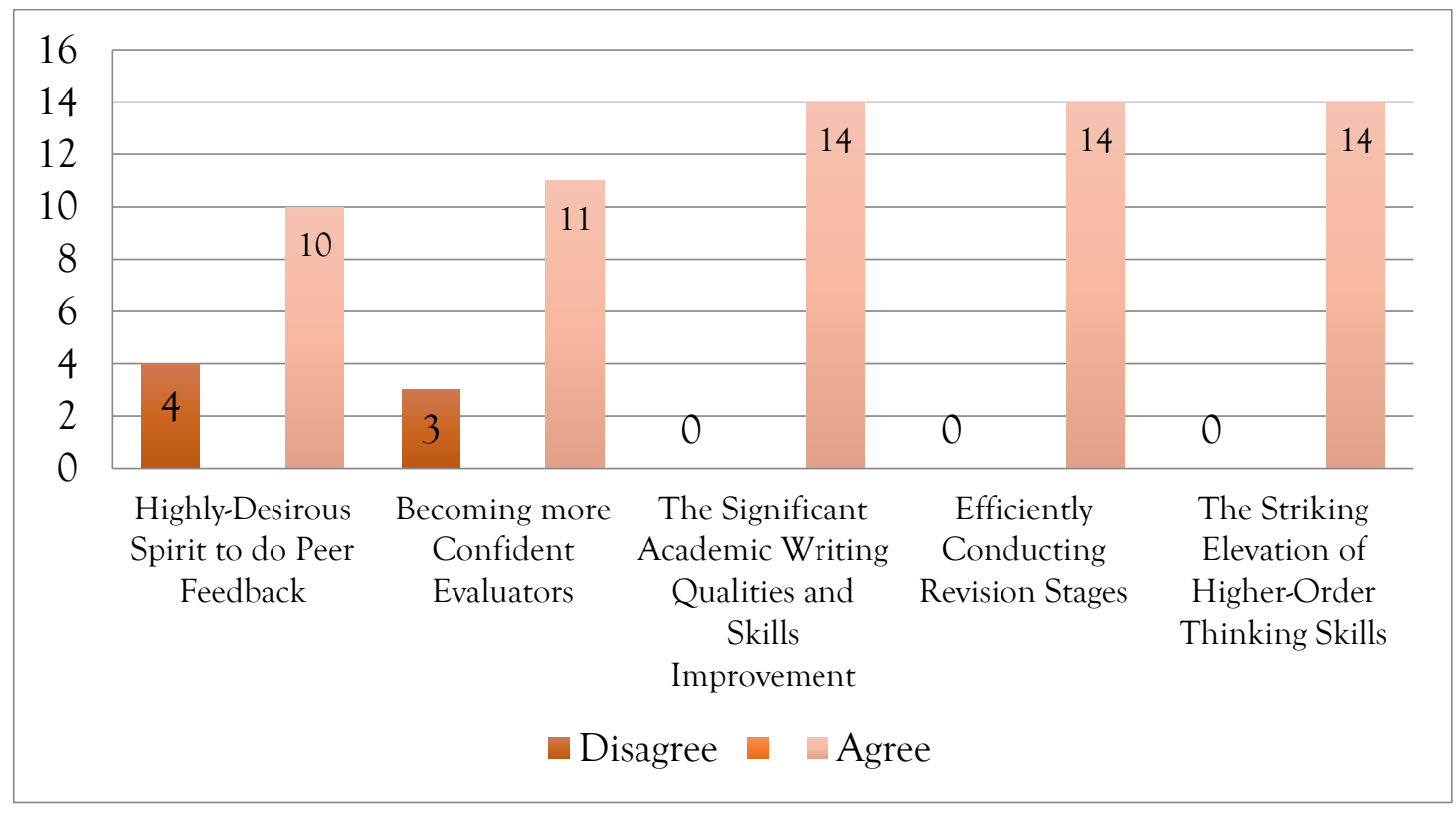

Figure 1. The Influential Positive Impacts Promoted by Peer Feedback (90\% Participants Agree) 
Notes:

-The Horizontal number represents the total number of research participants

-The Vertical number represents the total number of agreement

From the figure 1, it can be sensibly parsed here that the most participants agreed to constantly make use of peer feedback as one of their effective academic writing learning approaches since they become more competent writers and critical learners. Pitt et al. (2019) avowed peer feedback could be successfully utilized when EFL learners have possessed a strong mentality and robust intellectuals. Moving forward to the second finding, 11 out of 14 participants asserted that they have become more confident evaluators while addressing various constructive peer feedback for their targeted learning partners' academic writing products due to the insistent support addressed by their teachers. Simply stated, learners will be more eager to address a vast array of relevant peer feedback while discerning the positive responses from their learning counterparts. This may be specifically true for Allen and Katayama (2016), discovering that the most university EFL learners possessing a higher level of language learning proficiency will confidently address appropriate feedback for other learning companions.

Furthermore, learners had also successfully fostered their collaborative skills through the peer feedback since all learners work hand-in-hand other learning counterparts' existent understanding of the subject-specific matter. Through the utilization of peer feedback, EFL learners can reciprocally elevate their academic writing qualities and competencies to the utmost levels. Wakabayashi (2013) believed that in the light of peer feedback, EFL learners would be more capable of fostering their targeted writing products and competencies more effectively since they acquired in-depth writing conventions and structure from their learning partners. The peer feedback approach could also allow EFL learners to meaningfully and efficiently revise their existing academic writing products based on the suitable peers' suggestions. Berggren (2019) theorized that proficient EFL learners would be more capable of revising their writings meaningfully in line with the constructive peer feedback given by other learning companions.

Lastly, the ultimate findings showcased that peer feedback could also elevate EFL learners' higher-order thinking skills besides the targeted academic writing competencies. This 
is because all learners are required to address relevant and constructive feedback to their peers. This conception is closely associated with the prior finding unearthed by Farrah (2012) unfolding that most university EFL learners having been armed with more meaning-making peer feedback activities tended to be more proactive, critical, innovative, and confident academics throughout academic writing processes reciprocally resulted in the terrific escalation of their higher-order thinking skills.

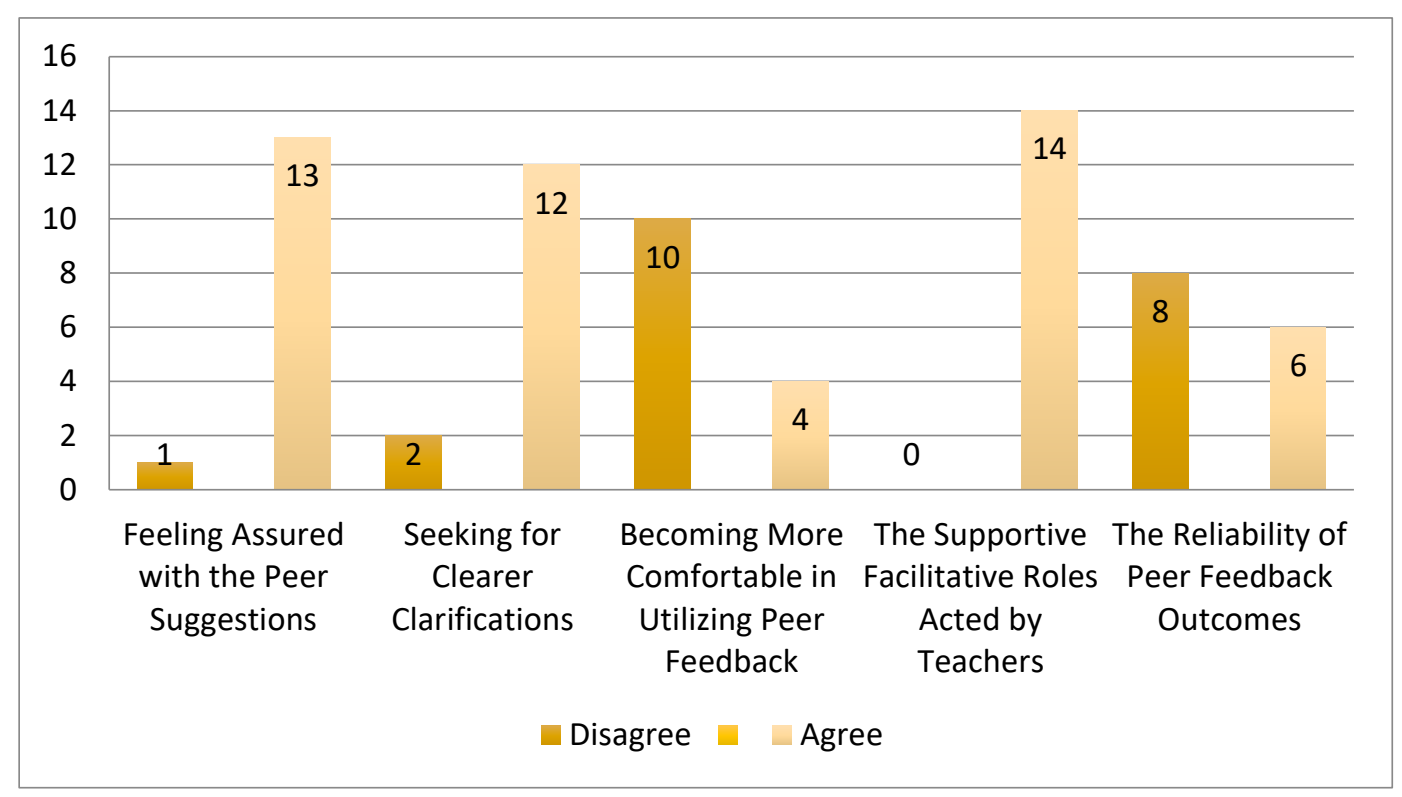

Figure 2. Factors Affecting the Utmost Utilization of Peer Feedback (61\% Participants Agreed)

Figure 2 focused on explicating a vast range of pivotal factors impacting the maximum internalization of peer feedback in academic writing learning dynamics. The first important factor that needs to be possessed by EFL learners is the strong beliefs toward the addressed peer feedback. 13 out of 14 research participants highly supported this premise. The more proficient the learners, the better peer feedback will be successfully imparted. Patchan and Schunn (2015) proved that most proficient university EFL learners could successfully address more meaningful peer feedback to their peers. In this case, it is undeniably stated that the gratifying academic writing achievements are strongly determined by the overall peer feedback qualities addressed by the reviewers. Positive responses toward the imparted peer feedback are another crucial matter urgently needed. 12 out of 14 research participants agreed with this third statement. However, this meaningful peer feedback occurrence can be ascertained when language teachers have 
played their roles as supporting academic writing learning facilitators Orsmond et al., (2013) highly encouraged EFL teachers to renew their roles as supportive academic writing facilitators in order to maximize the implementation of peer feedback.

Furthermore, 10 out of 14 participants strongly disagreed with the single utilization of peer feedback in academic writing learning ventures. They suggested that the integration between teacher and peer feedback needs to be infused strongly by EFL teachers introducing their learners to academic writing learning activities to constantly promote more conducive, stress-free, favorable, and meaningful knowledge discovery. Moore and Teather (2013) openly inviting worldwide EFL teachers to combine peer and their feedback to promote more positive academic writing learning climates. Furthermore, these participants also agreed that language teachers need to exhibit the appropriate approaches to magnify the peer feedback in academic writing to promote better learning outcomes for all learners. Roscoe et al., (2015) strongly suggested EFL teachers sustainably display various effective methods in utilizing academic writing peer feedback to transform all learners into more effective peer feedback users.

Ultimately, it can be clearly noticed that 6 out of 14 research participants agreed that peer feedback should be trustworthy, accurate, and reliable resulted in significant academic learning motivation. Hence, language teachers are prompted to encourage more contextual academic writing learning processes where all learners are strongly motivated. Rahimi (2013) highly encouraged globalized EFL teachers to continuously train their learners on how to address more constructive and appropriate peer feedback to other learning counterparts to holistically elevate all learners' academic writing competencies to the utmost potential.

\section{Data Obtained from the Interviewees:}

Peer Feedback Enabled Graduate University EFL Learners to be more Critical Academic Writers

In keeping with what had already been expounded previously, it is also interesting that peer feedback allowed graduate university EFL learners to be more critical academic writers. This first finding is emanated from 2 interviewees filling out 5 open-ended written narrative inquiry questions. They strongly believe that peer feedback had enabled them to become more socialized, critical, and respectful academicians while evaluating other's works. Kuyyogsuy 
(2019) strongly prompted EFL teachers to nurture peer feedback practices in academic writing learning ventures in order to better scaffold learners to develop their cognitive, affective, and social skills to the utmost potential. Johnson et al., (2017) also revealed that with the continual activation of peer feedback, graduate university EFL learners would be more capable of elevating their critical thinking, logical reasoning, and communicative skills more prolifically. 2 interviewees' excerpts also echoed the above-explained conceptions.

[Interviewee 1: Peer feedback allows you to see your own work from another perspective critically, making you notice mistakes you don't normally notice.]

[Interviewee 2: Peer feedback also trains students to be more careful, able to convey criticism well and appreciate the work of others.]

Further, the utilization of peer feedback can terrifically foster graduate university EFL learners' specific mindset and behaviors while receiving some inputs. 2 interviewees admitted that they did not feel offended anymore while receiving various constructive peer feedback from their learning partners. Reversely, they will become more open-minded in responding to those meaningful suggestions that resulted in the striking elevation of academic writing learning motivation. Latifi et al., (2021) uncovered that the majority of university EFL learners having been well-armed with the efficient and appropriate peer feedback practices were more capable of openly embracing all the specific suggestions put forth by learning peers. Shang (2019) highly advised globalized EFL teachers to nourish university EFL learners' academic writing volition by incorporating peer feedback activities in which they were able to openly, mutually, and collaboratively interchange various beneficial perspectives with others. 2 interviewees also raised identical argumentations in these following lines.

[Interviewee 1: Peer feedback are made from the perspective of a fellow student and not the teacher, which means that they raise different issues compared to actual feedback.]

[Interviewee 2: I think peer feedback lets me know how far I and my peers are in writing. In addition, we can also share opinions and information through feedback.] 


\section{The Qualities of Peer Feedback Mostly Depend on Evaluators' Reviewing Competencies}

One of the complex matters that language teachers ought to keep in mind before internalizing peer feedback practices in academic writing is the qualities, capabilities, and strategies graduate university EFL learners have to harness well before addressing various openended suggestions to their learning companions. It can also be stated that learners' skills heavily determine strength and efficiency of peer feedback in addressing more contextual as well as rewarding feedback to other learning community members. 2 interviewees avowed that although peer feedback had helped them extensively to smoothen their academic writing learning enterprises, they occasionally feel doubtful whether the suggestive inputs given by their peers are credible or not. Wu (2019) highly advocated EFL teachers to play their new roles as supportive academic writing learning facilitators in the midst of peer feedback activities integration to help learners to refine feedback addressed by their peers. Wahyudin (2018) also displayed that most university EFL learners who have transformed into successful academic writers are those whose learning motivation is continuously nurtured by supportive teachers' guidance and trustworthy feedback. All these lines of perspectives also hover in the mindset of the 2 interviewees.

[Interviewee 1: Sometimes, quality of peer feedback varies depending on the quality of the peers whether they have been trained in using this strategy previously or not.]

[Interviewee 2: I think my learning partners need to look at grammar, spelling, punctuation, then also to critique research methods, research questions, and effective writing formats. We should be trained to see these things clearly.]

To this end, another potential hurdle that can degrade the utmost utilization of peer feedback in academic writing is their existent target language learning competencies. Graduate university EFL learners will become more highly desirous of addressing various beneficial feedback toward their peers while they have been sufficiently-proficient in the target language. Therefore, Language teachers have to promote more supportive, pleasurable and relaxing academic writing learning environments where all learners possessing distinctive language learning proficiency are willing to participate in peer feedback activities. Pham et al., (2020) 
displayed that most university EFL learners who are being exposed to a more enjoyable, encouraging, and positive academic writing learning atmosphere are more liable to become more responsible evaluators for their peers. Wang (2014) strongly suggested EFL teachers mix up proficient and developing university EFL learners in particular peer feedback groups to escalate their confidence while carrying out peer feedback activities. These conceptions as mentioned earlier are also in the view of 2 interviewees in these following lines.

[Interviewee 1: I like peer feedback, I'm not embarrassed at all, or sad when my friends said there are a lot of mistakes in my writing because it makes me more careful later.]

[Interviewee 2: For me personally, the effective peer feedback can be experienced by all of us when ideally all learners are advanced, but it is better to expect that teachers can combine us with various learners' learning competencies to work more mutually wit each other.]

\section{Conclusion and Implication}

As a closing remark, the obtained research results above strongly suggested worldwide EFL teachers appropriately, efficiently, and meaningfully integrate the utilization of peer feedback with academic writing learning enterprises undergone by graduate university EFL learners. Loosely based on this context, it is of critical importance for language teachers to cultivate this contextual student-centered learning approach in their diverse wide-ranging academic writing learning circumstances since all learners will be more capable of elevating varied academic writing and future life skills simultaneously. One essential thing that needs to be pondered on is language teachers have to ensure that the utilization of peer feedback is suitably matched with the current learners' learning proficiency, needs, interest, conditions, and readiness unless this student-centered approach will not promote influential impacts toward their academic writing skills development.

Some particular research shortages are to be acknowledged. Firstly, since the researcher only relied on 2 research instruments in the data collection processes, it is worth suggesting that future researchers supplement one more research instrument, namely classroom 
observation to clearly discern the bigger pictures of the specific recurring phenomenon occurring in certain vicinities. Secondly, a great number of research participants enrolling in different universities will also bring about more significant research results for future researchers. Thus, they are strongly recommended to ponder more conscientiously over this suggestive advice before conducting an identical investigation. Irrespective of these aforementioned shortcomings, these existing research results had collectively shed more enlightenment for ELT experts, educators, practitioners, and policy-makers all around the globe to summon up peer feedback practices through academic writing learning enterprises in order to holistically breed more competent future target language academicians casting a higher degree of reverence to other learning community members.

\section{References}

Ajjawi, R., \& Boud, D. (2017). Researching feedback dialogue: An interactional analysis approach. Assessment and Evaluation in Higher Education, 42(2), 252-265. https://doi.org/10.1080/02602938.2015.1102863

Allen, D., \& Katayama, A. (2016). Relative second language proficiency and the giving and receiving of written peer feedback. System, 56, 96-106. https://doi.org/10.1016/j.system.2015.12.002

Allen, D., \& Mills, A. (2016). The impact of second language proficiency in dyadic peer feedback. Language Teaching Research, 20(4), 498-513. https://doi.org/10.1177/1362168814561902

Andrade, M. S., \& Evans, N. W. (2012). Principles and practices for response in second language writing: Developing self-regulated learners. Routledge.

Berggren, J. (2019). Writing, reviewing, and revising: Peer feedback in lower secondary EFL classrooms (Doctoral dissertation, Department of English, Stockholm University).

Bijami, M., Kashef, S. H., \& Nejad, M. S. (2013). Peer Feedback in Learning English Writing: Advantages and Disadvantages. Journal of Studies in Education, 3(4), 91. https://doi.org/10.5296/jse.v3i4.4314

Bacon, E. D., \& Bounty, T. (2020). Utilizing peer feedback by synthesizing a peer-assisted learning center with an English course to develop English grammar and academic writing skills. Rangsit Journal of Educational Studies, 7(1), 34-45. 
Cao, Z., Yu, S., \& Huang, J. (2019). A qualitative inquiry into undergraduates' learning from giving and receiving peer feedback in 22 writing: Insights from a case study. Studies in Educational Evaluation, 63, 102-112.

Carless, D., \& Boud, D. (2018). The development of student feedback literacy: enabling uptake of feedback. Assessment and Evaluation in Higher Education, 43(8), 1315-1325. https://doi.org/10.1080/02602938.2018.1463354

Chen, Y. S., \& Su, S. W. (2012). A genre-based approach to teaching EFL summary writing. ELT Journal, 66(2), 184-192. https://doi.org/10.1093/elt/ccr061

Cho, J. Y., \& Lee, E. H. (2014). Reducing confusion about grounded theory and qualitative content analysis: Similarities and differences. Qualitative Report, 19(32), 1-20. https://doi.org/10.46743/2160-3715/2014.1028

Clandinin, D. J., \& Caine, V. (2013). Narrative inquiry. Reviewing Qualitative Research in the Social Sciences, 166-179. https://doi.org/10.4324/9780203813324-13

Evans, C. (2015). Students' Perspectives on the Role of Peer Feedback in Supporting Learning. Journal of Cognitive Education and Psychology, 14(1), 110-125. https://doi.org/10.1891/1945-8959.14.1.110

Farrah, M. (2012). 4 The impact of peer feedback on improving the writing skills among hebron university students. An - Najah Univ. J. Res. (Humanities). Vol. 26(1), 2012. 26(1).

Fithriani, R. (2019). ZPD and the benefits of written feedback in 12 writing: Focusing on students' perceptions. The Reading Matrix : An International Online Journal, 19(1), 63-73.

Hirvela, A., \& Du, Q. (2013). “Why am I paraphrasing?”: Undergraduate ESL writers' engagement with source-based academic writing and reading. Journal of English for Academic Purposes, 12(2), 87-98. https://doi.org/10.1016/j.jeap.2012.11.005

Junianti, R., Pratolo, B. W., \& Tri Wulandari, A. (2020). The Strategies of Learning Writing Used by EFL Learners at a Higher Education Institution. Ethical Lingua: Journal of Language Teaching and Literature, 7(1), 64-73. https://doi.org/10.30605/25409190.131

Johnson, A. C., Wilson, J., \& Roscoe, R. D. (2017). College student perceptions of writing errors, text quality, and author characteristics. Assessing Writing, 34, 72-87.

Kita, K., Kobayashi, N., Ejiri, H., \& Yamashiro, S. (2010). Introducing Narrative Based Medicine to Medical Students: Story writing exercise from two viewpoints. Igaku Kyoiku/Medical Education (Japan), 41(4), 303-308.

Kuyyogsuy, S. (2019). Promoting Peer Feedback in Developing Students' English Writing 
Ability in L2 Writing Class. International Education Studies, 12(9), 76. https://doi.org/10.5539/ies.v12n9p76

Latifi, S., Noroozi, O., Hatami, J., \& Biemans, H. J. A. (2021). How does online peer feedback improve argumentative essay writing and learning? Innovations in Education and Teaching International, 58(2), 195-206. https://doi.org/10.1080/14703297.2019.1687005

Levitt, H. M., Bamberg, M., Creswell, J. W., Frost, D. M., Josselson, R., \& Suárez-Orozco, C. (2018). Journal article reporting standards for qualitative primary, qualitative metaanalytic, and mixed methods research in psychology: The APA Publications and Communications Board task force report. American Psychologist, 73(1), 26.

Mahdiya, M. A. (2021). Improving the Students' Writing Skill in Descriptive Text Through Picture Word Inductive Model. Jurnal Dialektika. 8(2), 147-155.

Moore, C., \& Teather, S. (2013). Engaging students in peer review: Feedback as learning. Issues in Educational Research, 23(2 SPL), 196-211.

Mutch, A., Young, C., Davey, T., \& Fitzgerald, L. (2018). A journey towards sustainable feedback. Assessment and Evaluation in Higher Education, 43(2), 248-259. https://doi.org/10.1080/02602938.2017.1332154

Nicol, D., Thomson, A., \& Breslin, C. (2014). Rethinking feedback practices in higher education: a peer review perspective. Assessment and Evaluation in Higher Education, 39(1), 102-122. https://doi.org/10.1080/02602938.2013.795518

Orsmond, P., Maw, S. J., Park, J. R., Gomez, S., \& Crook, A. C. (2013). Moving feedback forward: Theory to practice. Assessment and Evaluation in Higher Education, 38(2), 240-252. https://doi.org/10.1080/02602938.2011.625472

Patchan, M. M., \& Schunn, C. D. (2015). Understanding the benefits of providing peer feedback: how students respond to peers' texts of varying quality. Instructional Science, 43(5), 591-614. https://doi.org/10.1007/s11251-015-9353-x

Pham, T. N., Lin, M., Trinh, V. Q., \& Bui, L. T. P. (2020). Electronic Peer Feedback, EFL Academic Writing and Reflective Thinking: Evidence From a Confucian Context. SAGE Open, 10(1). https://doi.org/10.1177/2158244020914554

Pitt, E., Bearman, M., \& Esterhazy, R. (2019). The conundrum of low achievement and feedback for learning. Assessment $\mathcal{E}$ Evaluation in Higher Education.

Price, M., Handley, K., \& Millar, J. (2011). Feedback: Focusing attention on engagement. Studies in Higher Education, 36(8), 879-896. https://doi.org/10.1080/03075079.2010.483513 
Rahimi, M. (2013). Is training student reviewers worth its while? A study of how training influences the quality of students' feedback and writing. Language Teaching Research, 17(1), 67-89. https://doi.org/10.1177/1362168812459151

Rezeki, Y. S. (2017). Collaborative Written Feedback Experience: A Case Study of Indonesian EFL Students in an Essay Writing Class. International Journal of Educational Best Practices, 1(2), 24. https://doi.org/10.31258/ijebp.v1n2.p24-37

Roscoe, R. D., Snow, E. L., Allen, L. K., \& McNamara, D. S. (2015). Automated detection of essay revising patterns: Applications for intelligent feedback in a writing tutor. Grantee Submission, 10(1), 59-79.

Shang, H. F. (2019). Exploring online peer feedback and automated corrective feedback on EFL writing performance. Interactive Learning Environments, 0(0), 1-13. https://doi.org/10.1080/10494820.2019.1629601

Wahyudin, A. Y. (2018). The impact of online peer feedback on EFL students writing at tertiary level. BAHTERA: Jurnal Pendidikan Bahasa Dan Sastra, 17(1), 1-10. https://doi.org/10.21009/bahtera.171.1

Wakabayashi, R. (2013). The effects of the peer feedback process on reviewers' own writing. English Language Teaching, 6(9), 177-192. https://doi.org/10.5539/elt.v6n9p177

Wang, W. (2014). Students' perceptions of rubric-referenced peer feedback on EFL writing: A longitudinal inquiry. Assessing Writing, 19, 80-96. https://doi.org/10.1016/j.asw.2013.11.008

Winstone, N. E., \& Boud, D. (2020). The need to disentangle assessment and feedback in higher education. Studies in Higher Education, $0(0)$, 1-12. https://doi.org/10.1080/03075079.2020.1779687

Wu, Z. (2019). Lower English proficiency means poorer feedback performance? A mixedmethods study. Assessing Writing, 41(May), 14-24. https://doi.org/10.1016/j.asw.2019.05.001

Yu, S., \& Hu, G. (2017). Can higher-proficiency L2 learners benefit from working with lowerproficiency partners in peer feedback? Teaching in Higher Education, 22(2), 178-192. https://doi.org/10.1080/13562517.2016.1221806

Yu, S., \& Lee, I. (2016). Peer feedback in second language writing (2005-2014). In Language Teaching (Vol. 49, Issue 4). https://doi.org/10.1017/S0261444816000161

Zhou, J., Dawson, P., Tai, J. H. M., \& Bearman, M. (2021). How conceptualising respect can 
Journal of Foreign Language Teaching and Learning

Volume 7, No. 1, January 2022

Available online at: https://journal.umy.ac.id/index.php/FTL/issue/view/833

e-ISSN: 2580-2070, p-ISSN: 2527-7650

inform feedback pedagogies. Assessment and Evaluation in Higher Education, 46(1), 68-79. https://doi.org/10.1080/02602938.2020.1733490

Zhu, Q., \& Carless, D. (2018). Dialogue within peer feedback processes: clarification and negotiation of meaning. Higher Education Research and Development, 37(4), 883-897. https://doi.org/10.1080/07294360.2018.1446417 